\title{
LIÇÕES DA LÍNGUA MATERNA (1906): LIVRO DIDÁTICO DE GRAMÁTICA NA PARAÍBA PARA O ENSINO PRIMÁRIO ${ }^{1}$
}

\author{
Maria Daniela Ângelo Ramos ${ }^{2}$ \\ Fabiana Sena ${ }^{3}$
}

\section{RESUMO}

O presente trabalho tem como objetivo analisar a obra Lições da Língua Materna, de Francisco Xavier Junior, publicada em 1906, adotada, por meio do decreto $\mathrm{n}^{\circ} 315$ de 17 de janeiro de 1907, como único livro a ser utilizado nas escolas primárias da Paraíba para o ensino de língua portuguesa. Esse livro foi considerado como o primeiro livro de gramática para crianças produzido por um autor paraibano. A produção de livros no período republicano deveria valorizar o ensino da língua materna, pois era um meio de reforçar a ideia de que toda língua tem uma gramática. Para a análise, utilizamos Chartier (1999) e Foucault (2012) sobre autoria, processo de produção de obra e os protocolos de leitura. O autor de Lições da Língua Materna elaborou essa obra de acordo com a tendência de inovar os métodos de ensino da gramática da língua portuguesa baseado no método intuitivo, atendendo ao projeto modernizador republicano. Com efeito, ao ensinar saberes padronizados sobre a língua vigente a obra contribuiu com a tarefa de homogeneizar/unificar por meio de um referencial comum, a língua materna.

Palavras-chave: Gramática. Livro didático. República. Língua Materna.

\section{LIÇÕES DA LÍNGUA MATERNA (1906): GRAMMAR OF TEXTBOOK ON PARAÍBA FOR PRIMARY EDUCATION}

\begin{abstract}
This study aims to analyze the work Lições da Lingua Materna, Francis Xavier Junior, published in 1906, adopted by means of decree $n^{\circ} .315$ of January 17, 1907, as the only book to be used in primary schools Paraíba for the Portuguese language teaching. This book was considered as the first grammar book for children produced by a paraibano author. The production of books in the republican period should value the mother tongue teaching, it was a means of reinforcing the idea that all language has a grammar. For analysis, we use Chartier (1999) and Eddy (2012) on authorship, work producing process and the reading protocols. The author of Lições da Lingua Materna developed this work in accordance with this tendency to innovate grammar teaching methods of the Portuguese language based on the intuitive method, given the Republican modernizing project. Indeed, to teach standardized knowledge on the current language's work contributed to the task to standardize / unify through a common framework, the mother tongue.
\end{abstract}

Keywords: Grammar. Textbook. Republic. Mother Tongue.

\section{Considerações Iniciais}

O ensino de gramática esteve presente na história da língua portuguesa no Brasil desde a chegada dos jesuítas e da implantação das primeiras escolas de ler, escrever e contar. De acordo com Orlandi (2000, p. 34), para quem a gramática é a forma dominante de estudos da língua na Escola, "o ensino de português, língua nacional, está ligado à gramática. A partir do entendimento de que a língua é a marca de identidade de um povo, 
ou seja, a construção dessa identidade está vinculada à língua falada por este povo (CARVALHO, 2008), o seu estudo constitui uma fonte de pesquisa para a compreensão de um legado cultural e linguístico.

Nessa perspectiva, o estudo do livro didático oferece pistas significativas para a compreensão de uma situação de ensino brasileiro. Ao analisar o livro didático dos primeiros anos do século $\mathrm{XX}$, podemos identificar elementos que evidenciam a metodologia, a seleção do conteúdo, os objetivos do ensino da língua, os critérios de seleção de textos da época.

A aprendizagem de uma língua/gramática comum no Brasil, do final do século XIX e começo do século XX, influenciou o ensino, no sentido de fortalecer a ideia de nação na população, ou seja, de que um elemento comum, além do território, neste caso, a língua era essencial para o fortalecimento deste sentimento.

Tendo em vista que o saber sobre a língua foi um dos meios de representação de uma identidade nacional e linguística que se constituiu por meio do ensino de gramática, interessamo-nos em dar visibilidade ao livro didático Lições da Língua Materna, publicado em 1906, de autoria do paraibano Francisco Xavier Junior. Embora não se tenha dados da sua circulação nas escolas da Paraíba, buscamos analisar essa obra, por compreender que "o livro didático interessa igualmente a uma história da leitura porque ele, talvez mais ostensivamente que outras formas escritas, forma o leitor" (LAJOLO e ZILBERMAN, 2009, p.121).

O interesse em dar visibilidade a uma obra até então esquecida nas bibliotecas e arquivos do Estado da Paraíba nos possibilitou conhecer como eram encaminhadas as situações de ensino de gramática no cotidiano escolar da Paraíba. Portanto, este bem cultural se constitui como objeto e fonte para estudar a História da Educação na Paraíba por meio do ensino e das disciplinas escolares.

Dessa forma, compreender o livro didático na História da Educação permitiu tomar conhecimento de como Lições da Língua Materna contribuiu para a organização da cultura escolar, bem como por se configurar como

[...] um tipo de material de significativa contribuição para a história cultural e das práticas educativas ao lado de outras fontes escritas, orais e iconográficas e, segundo, ser portador de conteúdos reveladores de representações e valores predominantes num certo período de uma sociedade que, simultaneamente à historiografia da educação e da teoria da história, permitem rediscutir intenções e projetos de construção e de formação social. (CORRÊA, 2000, p. 11).

É possível constatar que Lições da Língua Materna apresenta uma proposta metodológica para o ensino de gramática específica para uma determinada etapa do ensino - no caso, o primário -, diferente dos métodos que eram utilizados nesse período no Estado da Paraíba, baseados unicamente no exercício de memorização de regras e exceções. Francisco Xavier Junior elaborou esse livro para servir de manual aos educadores paraibanos, pois não havia ainda "um trabalho que satisfizesse as necessidades do ensino elementar da língua pátria" (XAVIER JUNIOR, 1906, p. XI). Esse livro é considerado como o primeiro livro de gramática produzido na Paraíba no início do século XX, pois, até então, eram utilizadas gramáticas advindas da Europa, mais especificamente de Portugal, conforme afirma Sena (2008). O autor era professor de Latim, Português, Geografia e História do Brasil, no Liceu Paraibano e que exerceu também a Diretoria desta instituição e da Escola Normal Oficial durante o período de 1908 a 1912, além da Direção da Instrução Pública de 1912 a 1915. 
Em relação à língua portuguesa, era um momento efervescente de ideias, uma vez que muitas obras literárias de autores brasileiros estavam sendo produzidas. Pregava-se ruptura e inovação no ensino do português, pois havia nesse momento a "preocupação com a disseminação da alfabetização e com o saber a ser veiculado pela escola, a nova instituição que se impunha como necessidade da vida civilizada" (BITTENCOURT, 1993, p. 28). A publicação do livro Lições da Língua Materna, em 1906, se deu logo após os primeiros anos da instauração do regime republicano, momento de impulsão e crescimento da produção de obras didáticas de autores nacionais com vistas a internalizar o nacionalismo nas crianças do ensino elementar. Podemos supor que esse tenha sido um dos motivos por que levou o autor a elaborar a obra. Naquele período, o livro foi adotado como único a ser utilizado nas escolas públicas do ensino primário na Paraíba e circulou até o ano de 1947, conforme constatado em publicação do Diário Oficial da União (DOU). Tal dado nos possibilita supor que a obra circulou durante muito tempo no Estado da Paraíba.

Dessa forma, por meio do estudo do livro Lições da Língua Materna, de Francisco Xavier Júnior, buscamos compreender as propostas e os métodos para o ensino de gramática na escola elementar primária no início do século $\mathrm{XX}$, atentando aos objetivos e interesses relacionados ao ensino da língua materna.

\section{Sobre o ensino de gramática na Paraíba}

Até a segunda metade do século XIX, o ensino da gramática na Paraíba seguia um padrão baseado no estudo dos clássicos, do latim, retórica e poética, que não trazia simplicidade nem clareza para o ensino de língua. Essa tradição permaneceu por um longo período, baseado nos ideais de falar bem e escrever bem $^{4}$, e manteve seu status de destaque na sociedade. Prevaleciam os antigos métodos voltados para formar uma elite culta e religiosa, que aprendia a arte de falar e escrever corretamente.

Os métodos utilizados estavam preocupados em valorizar a experiência e o passado. Além disto, fatores externos contribuíram para manter o padrão no ensino de gramática, não havendo motivos para a mudança, pois,

[...] fundamentalmente, continuaram a ser os mesmos aqueles que a escola servia: os grupos social e economicamente privilegiados, únicos a ter acesso à escola; pertencentes a contextos culturais letrados, chegavam às aulas de português já com um razoável domínio do dialeto de prestígio (a chamada norma culta padrão), que a escola usava e queria ver usado, e já com práticas sociais de leitura e escrita frequentes em seu meio social (SOARES, 1998, p. 01).

Os objetos e objetivos para o ensino de gramática que haviam se constituído, ao longo da história no Brasil, tornaram seu ensino algo não funcional e desarticulado com a realidade de uso da língua. Um ensino baseado na orientação humanística na qual a função básica com o ensino de língua portuguesa era:

Levar [o aluno] ao conhecimento, talvez mesmo ao reconhecimento, das normas e regras de funcionamento [do] dialeto de prestígio: ensino de gramática, isto é, ensino a respeito da língua, e análise de textos literários, para estudos da Retórica e Poética. (SOARES, 2006, p. 01)

Com a expansão da educação, a partir da segunda metade do século XIX, houve a propagação das ideologias nacionalistas. Nesse contexto, o ensino de gramática ganhou 
novas proporções, passando a ser estudado sob a luz da ciência do ponto de vista científico, dando início a um processo de gramatização da língua. Esse movimento buscava demonstrar as especificidades do português brasileiro, diferenciando-o do português de Portugal, o que impulsionou a produção de instrumentos primordiais para o ensino de língua, os dicionários e as gramáticas. O saber sobre a língua foi, pois, um dos meios de representação de unidade Nação/Estado.

Dessa forma, ao longo do século XIX, a identidade linguística, constituída por meio do ensino de gramática, funcionou como uma identidade nacional efetivada por meio da língua. Buscava-se com a gramática normatizar o campo educativo, a fim de uniformizar as práticas pedagógicas.

\section{Francisco Xavier Junior e as Lições da Língua Materna}

As orientações tradicionais trazidas do século XIX para a educação paraibana continuavam nas primeiras décadas do século XX, o que significava que o estudo do latim, a leitura de textos de autores consagrados para que a sua escrita servisse de exemplo para o bom uso do português escrito e reforçasse ao mesmo tempo o domínio da norma culta da língua pelos alunos.

Em meio a perspectiva da produção dos diversos manuais ${ }^{5}$ para o ensino de língua materna no ensino primário, destinado ao público infantil, Francisco Xavier Junior elaborou Lições da Língua Materna (Imagem 1) para que o ensino de gramática fosse funcional, tendo em vista que a língua portuguesa como língua pátria e oficial da educação precisava ser ensinada de uma maneira que fosse acessível à realidade dos alunos. Assim, a proposta era a de um "trabalho que satisfizesse as necessidades do ensino elementar da língua pátria” (XAVIER JUNIOR, 1906, p. XI).

Imagem 1 - Capa do livro Lições da Língua Materna de Francisco Xavier Junior, publicado em 1906 na Paraíba.

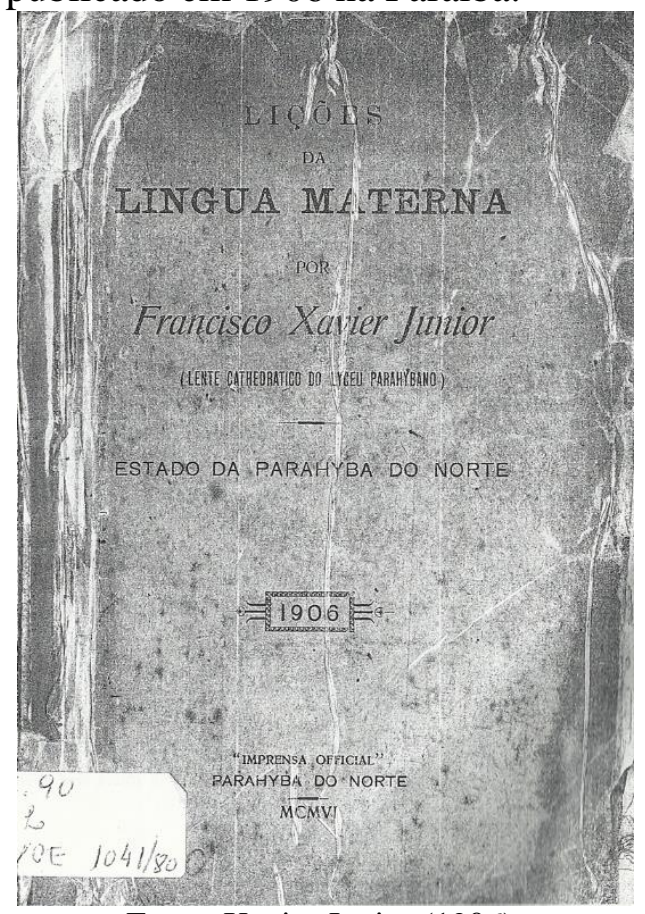

Fonte: Xavier Junior (1906). 
O ensino de língua presente na obra em análise previa reforçar a ideia de que toda língua tem uma gramática, responsável por colocar sob a forma de leis ou regras as tendências de linguagem de um grupo linguístico específico que marcava sua identidade nacional. Dentro desse entendimento, Francisco Xavier Júnior, ao propor uma gramática que estivesse em harmonia com os "modernos processos da psychologia pedagógica" (XAVIER JUNIOR, 1906, p. XI), baseados no método intuitivo, reforçava os discursos nacionalistas que tinham a intenção de, com o ensino de língua materna, unificar, por meio de um conjunto de valores, regras e ideais, os membros de uma sociedade que encontrariam um referencial comum, uma identidade social, aprendendo os saberes padronizados sobre a língua vigente.

No início no século XX, devido às diversas manifestações e interesses a favor da nacionalização dos livros (produção) escolares e da ampliação das escolas primárias, a produção e venda das obras didáticas foi impulsionada. É nesse contexto que a obra Lições da Língua Materna é idealizada e produzida, por se tratar de um momento de fortes expectativas em relação à educação, pois, além do dinheiro (que viria com a venda do material), trazia muito prestígio ao autor (e aos participantes) (SENA, 2008). Considerando que os livros são pensados e elaborados para atender a determinadas demandas da época em que são produzidos, eles

[...] são objetos cujas formas comandam, se não a imposição de um sentido ao texto que carregam, ao menos os usos de que podem ser investidos e as apropriações às quais são suscetíveis (CHARTIER,1999, p. 8).

O perfil das gramáticas utilizadas até então, segundo o professor Francisco Xavier Junior, seguia um processo muito cansativo, no qual os manuais forneciam as exposições das regras gramaticais e sem propositura de exercícios que estimulassem o raciocínio. De acordo com o autor, tal procedimento metodológico se apresentava "com flagrante violação dos cânones da pedagogia moderna, [sacrificavam] sacrificam a atividade intelectual do menino, obrigando-o a representar o papel de recipiente passivo de fórmulas e definições grammâticaes" (XAVIER JUNIOR, 1906, p. XI).

Com o propósito de ensinar gramática por meio do método intuitivo, Francisco Xavier Junior acreditava que tão-somente os exercícios poderiam trazer conhecimentos úteis. Assim, a partir da formação de frases, as crianças iriam aprender a língua, sem o entediante método de memorização de fórmulas e regras. Para ele, "maior trabalho para o mestre e pequeno esforço intelectual por parte do alumnozinho é o método que adopto e o único que deve ser observado pelo professor bem orientado" (XAVIER JUNIOR, 1906, p. XII).

O autor da obra didática afirma que, para a elaboração de seu trabalho, "forneceram bastos recursos, além da longa prática de ensino, os conselhos, as lições e exercícios da obra Lições de Coisas de Calkins, tradução do Dr. Rui Barbosa" (XAVIER JUNIOR, 1906, p. XI). Tal afirmação nos leva ao entendimento de que o autor de Lições da Língua Materna estava reproduzindo, de certa forma, o discurso modernizador de educação, pois assegurava que seu livro fora construído utilizando o que havia de mais avançado nos métodos de ensino da pedagogia moderna, no caso os preceitos do método intuitivo. Nada mais objetivo naquele momento do que preparar uma gramática baseada no método de Lições de Coisas (1861), de Norman Calkins, que era a representação do que havia de mais inovador na educação do país. E na Paraíba se fazia presente tal obra, conforme o anúncio abaixo do jornal $O$ Estado da Paraíba, tendo como um dos diretores o próprio Francisco Xavier Júnior. 


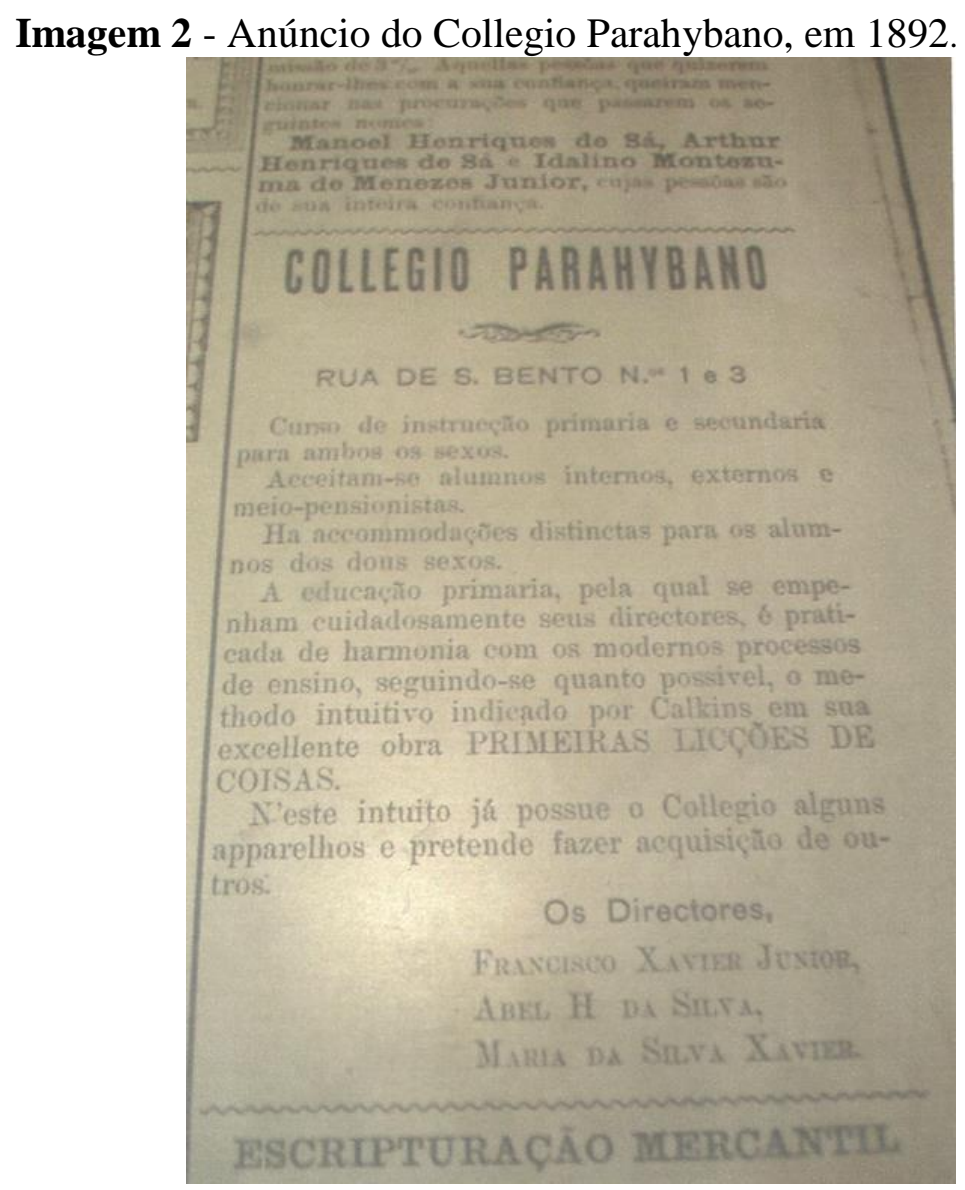

Fonte: Jornal o Estado da Paraíba, 1982.

\section{Os discursos sobre Lições da Língua Materna: os protocolos de leitura da obra}

Os discursos no prefácio da obra são de pessoas que ocupavam lugares de destaque dentro da sociedade paraibana da época. Estes se localizam antes da obra, do conteúdo didático propriamente dito, provavelmente no intuito de dar mais validade ao livro, junto ao leitor, pois ao fazer a leitura dessas opiniões passaria a ser visto como obra de significado e importância.

A construção de uma obra depende das demandas sociais, culturais e políticas, porque os livros escolares, de maneira geral, são um objeto em circulação e, em razão disso, funcionam como meio de disseminação de ideologias, valores e até mesmo comportamentos que almejavam ser ensinados na escola (CHARTIER, 1990). Ainda segundo este autor:

[...] os princípios que governam a 'ordem do discurso' pressupõe decifrar, com todo o rigor, aqueles outros que fundamentam os processos de produção, de comunicação e de recepção dos livros (e de outros objetos que veiculem o escrito) (CHARTIER, 1999, p. 8).

O primeiro discurso presente em Lições da Língua Materna é do jornal D'O Commercio $^{6}$. Este se inicia com elogios sobre o autor da obra, que aponta brevemente 
sobre sua vida enquanto estudante, profissional e político, servindo de uma apresentação das credenciais de Francisco Xavier Junior. O redator do jornal evidencia, assim, que o autor se trata de uma pessoa conhecida e letrada:

Xavier Junior é um nome já bastante conhecido nesta terra, onde quantos o conhecem rendem-lhe as homenagens merecidas por um espírito profundamente cultivado nas letras. Estudante que foi de uma aplicação excepcional, ninguém, nesta terra, é mais do que ele aparelhado em humanidades e, obedecendo a uma sede inexgotavel de saber, esse nosso caro patrício, arredado do bulício monótono da politica e do dessorante meio do funcionalismo publico, em que já figurou exercendo cargos de alta importância, não tem encontrado limites á sua vontade tenacíssima de illustrar-se. (D'O COMMERCIO, apud XAVIER JUNIOR, 1906, p. I).

Compreendemos que os discursos têm como objetivo aprovar a referida obra, uma vez que se trata da primeira gramática paraibana. Francisco Xavier Junior, contemplando "a situação precária da instrução publica da Parahyba, (...) deo-nos a grata nova de que tinha entre mãos um trabalho concernente ao assumpto" (D'O COMMERCIO, apud XAVIER JUNIOR, 1906, p. II). Portanto, segundo a opinião do jornal, a obra seria uma solução, pelo menos em relação ao ensino de língua portuguesa no primário. Um livro necessário, tendo em vista que respondia às necessidades de mudanças no programa e no método de ensino de gramática na educação infantil.

[...] grammatica! Um methodo de ensino para mocidade de nossa terra! Um escrínio de alimentos espirituáes, recalcados nos mais modernos processos do magistério, remodelado pela pratica, adaptado pela experiência á assimilação do espirito infantil! (D'O COMMERCIO, apud XAVIER JUNIOR, 1906, p. II).

Ao utilizar o termo 'moderno', o jornal D'O Commercio estava colocando o livro numa posição de destaque, pois indicava o seu potencial inovador, seguindo o que havia de melhor em termos de métodos de ensino. Se o ensino de gramática era baseado na monotonia da memorização de regras, ou seja, direcionado à aprendizagem das normas ortográficas, apreendidas por meio da cópia e do ditado, a proposta metodológica em Lições da Língua Materna, conforme acrescenta o jornal, divergia de certa maneira com essa proposta de ensino utilizada. Nesse sentido, o jornal considera que possui

[...] exercicios proveitosíssimos, delineados methodicamente, desde os mais simples aos mais compostos; explicações theoricas e praticas de construção da frase e da proposição; e tudo mais que é indispensável aprender nas escolas inferiores, para se passar vantajosamente aos cursos secundários, nós encontramos, abundantemente selecionado no trabalho de Xavier Junior. (D’O COMMERCIO, apud XAVIER JUNIOR, 1906, p.III).

Posicionamente semelhante apresenta o jornal A União ${ }^{7}$, para quem Lições da Língua Materna é considerada "uma primorosa e bem feita grammatica para uso das escolas primarias" (A UNIÃO ${ }^{8}$, apud XAVIER JUNIOR, 1906, p. IV). Conforme afirma o jornal, a gramática atendeu a todas as exigências em termos de qualidade pelo fato de "todas as partes da sua grammatica que nos foi dado apreciar estão organizadas de uma 
maneira clara e methodica, atestando que presidio á sua confecção a alta competência de um mestre, um senhor da materia" (A UNIÃO in: XAVIER JUNIOR, 1906, p. IV).

Ainda conforme A União:

[...] as grammaticas têm sido horrorosos tormentos para as creanças que se viciam a decorar aquilo que não entenderam. O livro do sr. Xavier Junior baseia-se nos processos suaves com que se poderão dar as noções grammaticaes aos jovens alunos (A UNIÃO in: XAVIER JUNIOR, 1906, p. V).

Chartier (1999, p. 9) assegura que "certamente os criadores, os poderes ou os experts sempre querem fixar um sentido e enunciar a interpretação correta que deve impor limites à leitura (ou ao olhar)". Nesse sentido, o autor Francisco Xavier Junior buscou fixar a ideia de que, até então, todas as gramáticas produzidas e utilizadas para o ensino primário no Estado da Paraíba, por meio dos discursos que se apresentam no livro, não estavam em harmonia com o espírito ${ }^{9}$ das crianças, e que o ensino da gramática da língua materna havia se tornado um tormento. Acerca do assunto, o jornal A União faz a seguinte apreciação:

[...] de um livro, organizado com methodo, em que se procure ensinar o alumno de uma maneira quase recreativa, agradando-o, pondo diante de seus olhos o que se necessita que conheça, que ao mesmo tempo satisfaça o seu espirito irrequieto, eis o que se torna necessário para o ensino da grammatica nas escolas primarias. (...) Foi assim calcado o livro do talentoso professor Xavier Junior. (A UNIÃO in: XAVIER JUNIOR, p. V).

Conforme já apontamos, o livro segue o ensino intuitivo, de modo que o autor buscou desenvolver da prática à teoria, partindo do mais simples para o mais complexo, aquilo que já é conhecido pelo aluno, respeitando suas limitações, seus conhecimentos e necessidades para o planejamento do método de ensino. Nesse sentido, João Pereira de Castro Pinto, na época deputado federal, tece o seguinte comentário sobre a obra:

[...] tornar o mais possivel attrahente e suave o trabalho escolar, fazendoo intuitivo, gradual e concreto, de acordo com as faculdades em formação no cérebro do almno, converter o velho habito de memorisar abstracções no processo evolutivo de assimilar as noções quase espontaneamente, cabendo ao mestre o papel de dirigir, de modo adequado, a curiosidade táo natural aos meninos, eis o que a pedagogia moderna aconselha, e o que $\mathrm{V}$. procurou, com muita felicidade, aproveitar no ensino da grammatica (PINTO in: XAVIER JUNIOR, 1906, p. VI).

A rotina dos exercícios, como fora dito, torna inútil o planejamento, pois o método era tradicional, abstrato, não estimulava o raciocínio e dificultava a assimilação do conteúdo. Assim, "apesar de várias grammaticas destinadas ao ensino elementar, todas ellas eivadas do espirito de rotina, inábeis para o mister a que se destinam (PINTO in: XAVIER JUNIOR, 1906, p. VI).

Em Lições da Língua Materna, por meio desse método, há uma aproximação ao mesmo tempo entre os exercícios de memorização das regras da gramática, a linguagem e o processo de aprendizagem infantil, tornando a instrução pública familiar à criança. 
Os discursos apresentados na obra demonstram a importância que a própria obra teve na e para a Paraíba, em virtude de ser considerada a primeira gramática no estado que utiliza o método intuitivo, elaborada por um professor paraibano, como nos assegura Pinto (In: XAVIER JUNIOR, 1906, p. VI):

[...] o methodo que V. empregou na confecção das "Lições da Língua Materna" é fundado na experiência inteligente e meditada, e calca-se nos princípios da psychologia do ensino, consulta as verdadeiras necessidades da educação infantil, e vem preencher uma lacuna das 60 mais sensíveis na organisação racional das primeiras letras.

Esses pareceres sobre o livro ressaltam seu caráter inovador em relação às demais produções de gramática, embora outras não fossem citadas utilizadas na época. Esse tipo de comportamento, na opinião de Foucault (2012), de determinar as condições de funcionamento do discurso objetivava

[...] impor aos indivíduos que os pronunciam certo número de regras e assim de não permitir que todo mundo tenha acesso a eles. Rarefação desta vez dos sujeitos que falam; ninguém entrará na ordem do discurso se não satisfazer a certas exigências ou se não for, de início, qualificado para fazê-lo (FOUCAULT, 2012, p. 35).

Os discursos apresentados também estão na perspectiva de qualificar a obra, de fazê-la ser aceita pelo público leitor. Afinal, eram os jornais de grande circulação e homens de letras que validavam esse bem cultural. Considerando que "[...] a leitura não está, ainda, inscrita no texto, e que não há, portanto, distância pensável entre o sentido que lhe é imposto (por seu autor, pelo uso, pela crítica, etc.) e a interpretação que pode ser feita por seus leitores" (CHARTIER, 1999, p. 11), o autor se preocupou construir significações nas leituras de sua obra, ao invés de deixar que o próprio leitor atribuísse seus sentidos a ela.

Na Paraíba, o discurso do Conselho Superior de Instrucção Publica é de que a educação também não acompanhou esse ritmo de 'mudanças' do início da República, uma vez que o ensino da língua materna, baseado no método dedutivo, não desenvolvia a inteligência dos alunos, que se tornavam reprodutores de regras, sem compreender o conteúdo,

[...] assim vemos com pesar nossas escolas primarias colocarem-se nas mãos das crianças compêndios para o estudo da língua materna calcados nos moldes do methodo deductivo, recheados de regras e de excepções cuja compreensão supõe um desenvolvimento intelectual que o alumno não pode ter ainda. E, na impossibilidade de fazer compreender, o professor faz decorar (XAVIER JUNIOR, 1906, p. VIII).

Sobre a metodologia, o Conselho Superior de Instrucção Publica da Parahyba afirma que o livro apresenta o método indutivo em substituição ao dedutivo, levando em conta que parte da prática para a teoria, e não o contrário como o anterior, agilizando, assim, o processo de assimilação do aprendiz, tendo em vista que

Outro é methodo a que obedece o livro que examinamos. Seguindo os salutares distames do methodo inductivo, ele não apresenta regra ou a definição, que sào sempre generalizações, sinão após ter feito no espírito do escolar a compreensão da matéria por uma serie de exercícios práticos, 
tendo assim habilitado a conceber o alcance e a extensão da generalização (XAVIER JUNIOR 1906, p. IX).

Portanto, os discursos sobre Lições da Língua Materna, que se apresentam no início da obra, apreciam esse material didático, ressaltando o método e o autor, apontando o lugar de destaque que essa obra tem para o cenário paraibano, já que objetiva inovar o ensino por meio da utilização dos preceitos da pedagogia moderna.

Quanto ao discurso do próprio autor do livro, Francisco Xavier Junior exibe a relevância e a necessidade da obra para a educação paraibana, comentando sobre a razão por que o levou a elaborar tal empreendimento. As suas palavras legitimam os discursos anteriores, ratificando o tom de verdade, pois, como afirma Foucault (2012, p. 26), o discurso do autor é indispensável por constituir um indicador de verdade por ser "[...] aquele que dá à inquietante linguagem da ficção suas unidades, seus nós de coerência, sua inserção no real"'.

Ao compreender que os discursos não são homogêneos, mas resultantes de uma heterogeneidade e o que é dito traz em si a presença do outro, já que os discursos estão permeados por outras vozes, Francisco Xavier Junior afirma que: "constrange-me ver ainda adoptada em nossas escolas primarias a velha prática de ensinar a crianças a língua materna pelo processo de fazel-as decorar regras e definições de grâmmatica" (XAVIER JUNIOR, 1906, p. XI). Aqui o autor traz outras vozes para compartilhar a mesma percepção do método de ensino da língua portuguesa na época. Assim, no discurso do autor de Lições da Língua Materna, a linguagem exerce um poder, uma autoridade resultante das posições por ele ocupadas, a de autor, professor e político.

A cultura da memorização, de acordo com o autor do livro didático, feria as propostas de ensino do que era considerado a 'pedagogia moderna' na época, e o ensino da língua materna apenas "sacrificavam a atividade intelectual do menino, obrigando-o a representar o papel de recipiente passivo de fórmulas e definições grammâticaes". (XAVIER JUNIOR, 1906, p. XI).

Outro ponto enfatizado pelo autor diz respeito à estruturação das lições que foram pensadas de forma a acompanhar o ritmo de desenvolvimento da inteligência da criança, dando prioridade ao seu aprendizado ao invés de se preocupar apenas em transmitir o conteúdo. Assim, as atividades se apresentam com o seguinte propósito:

[...] exercicios e as lições em que se divide, obedecem á ordem natural do desenvolvimento que vae adquirindo a inteligência do menino. Convem, portanto, que essa ordem não seja alterada, e que o alumno só passe para outra lição quando se achar bem familiarizado com os exercicios da precedente (XAVIER JUNIOR, 1906, p. XIII).

O autor também sugere que a gramática fosse pensada principalmente para servir de manual para aos mestres no ensino da língua materna, tendo como objetivo:

[...] ministrar ao mestre um método racional a seguir no ensino elementar da 69 linguagem. Este livro representa a consubstanciação do que seu autor colheu em obras preciosas sobre o assumpto e do que lhe forneceu experiência de uma longa pratica no magistério, tendo procurado inspirarse no método da psychologia do ensino (XAVIER JUNIOR, 1906, pp. XII - XIII). 
Estimulado pelo "nobre empenho em que se acha a administração publica do Estado, de remodelar a instrucção primaria" (XAVIER JUNIOR, 1906, p. XII), o autor publica a sua obra didática, tendo nela discursos que concretizam os objetivos do autor: de tornar aos olhos do público a primeira gramática para crianças paraibana por meio de um método inovador.

\section{Considerações Finais}

Dar visibilidade ao livro Lições da Língua Materna, publicado em 1906, da autoria de Francisco Xavier Junior, para o ensino de gramática na escola elementar paraibana no início do século XX, permite reconstruir saberes sobre o ensino de língua portuguesa na Paraíba.

Os protocolos de leitura na obra com discursos que a apreciam positivamente possibilitam construir uma representação de Francisco Xavier Junior como autor de livro didático, já que essa posição "demonstra a busca pela consagração, ocupando uma posição entre um filão da indústria do livro didático bastante importante à época dos autores de sucesso de livros didáticos" (SENA, 2011, p. 77). A presença dos discursos do Governo do Estado, do Conselho de Instrução pública, dos jornais da época, A União e Jornal D'O Commercio, e do Deputado Federal, Castro Pinto, contribuiu para que livro fosse adotado como material oficial a ser utilizado nas escolas públicas da Paraíba, configurando-se como uma estratégia de validação do modo de leitura do público.

Assim, não se tratava apenas de apresentar discursos sobre a obra didática de gramática, mas de mostrar ao público leitor que mais que um livro necessário, inovador e moderno era um material do Governo, pois foi escrito, aprovado e publicado pelo poder estatal, inclusive carregando seu nome na capa, o que já era suficiente para que o livro fosse aprovado. Essa estratégia pode se configurar para validar o livro junto ao público - as autoridades escolares, os professores, os pais e os alunos.

Lições da Língua Materna seguiu a tendência de inovar os métodos de ensino da gramática de língua portuguesa baseado no método intuitivo. Por meio dele, foi possível circular saberes padronizados sobre a língua vigente, de modo que a obra contribuiu com a tarefa de homogeneizar/unificar a partir de um referencial comum, a língua materna. Assim, o estudo do livro didático permite entender a organização escolar e a sociedade da época em que foi produzido por ser um objeto cultural datado.

\section{Referências}

A UNIÃO. Livro Escolar. In: XAVIER JUNIOR, Francisco. Lições da Língua Materna. Parahyba do Norte: Imprensa Oficial, 1906.

CARVALHO, José Ricardo. A construção da identidade de uma nação por meio da língua escrita e falada. Revista Fórum Identidades, Sergipe, 2, 83-90, 2008.

CHARTIER, Roger. A história cultural: Entre práticas e representações. Lisboa: Difel, 1990.

. A ordem dos livros: leitores, autores e bibliotecas na Europa entre os séculos XIV e XVIII. Trad. Mary Del Priore. 2. ed. Brasília/DF: UnB, 1999.

CORRÊA, Rosa Lydia Teixeira. O livro escolar como fonte de pesquisa em História da Educação. Cadernos Cedes, São Paulo, n 52, p. 11 -24, 2000. 
D'O COMMERCIO. Instrucção Publica: um livro necessário. In: XAVIER JUNIOR, Francisco. Lições da Língua Materna. Parahyba do Norte: Imprensa Oficial, 1906. ESTADO DA PARAÍBA. Anúncio Collegio Parahybano, 1892.

FOUCAULT, Michel. A ordem do discurso. 22. ed. São Paulo: Edições Loyola, 2012.

LAJOLO, Marisa e ZILBERMAN, Regina. A Formação da Leitura no Brasil. 3. ed. São Paulo: Ática, 2009.

ORLANDI, Eni P. Metalinguagem e gramatização no Brasil: gramática-filologialinguística. In: Rev. ANPOLL, n. 8, p. 29-39, jan./jun. 2000.

PINTO, João Pereira de Castro. Amigo Xavier Junior. In: XAVIER JUNIOR, Francisco. Lições da Língua Materna. Parahyba do Norte: Imprensa Oficial, 1906.

SENA, Fabiana. A tradição da civilidade nos livros de leitura no império e na primeira república. Programa de Pós-Graduação em letras da Universidade Federal da Paraíba: Tese de Doutorado, 2008.

SENA, Fabiana. A imprensa e Carlos Dias Fernandes: o processo de legitimação como autor de livro didático. Educação Unisinos. 15(1):70-78, janeiro/abril 2011. Disponível em: revistas.unisinos.br/index.php/educacao/article/download/218/191. Acesso em 27 de maio de 2015.

SOARES, Magda. Becker. Concepções de linguagem e o ensino da língua portuguesa. In: Neusa Barbosa Bastos (org). Língua portuguesa: história, perspectivas e ensino. São Paulo: EDUC, pp. 53-59, 1998.

Letramento: um tema em três gêneros. Belo Horizonte: Autêntica, 2006.

XAVIER JUNIOR, Francisco. Lições da Língua Materna. Parahyba do Norte: Imprensa Oficial, 1906.

\footnotetext{
${ }^{1}$ Trabalho realizado com o apoio da Capes.

${ }^{2}$ Mestre em Educação pela Universidade Federal da Paraíba.

${ }^{3}$ Pós-doutora em Educação pela Universidade Estadual do Rio de Janeiro. Professora Adjunta da Universidade Federal da Paraíba. Atua no Programa de Pós-Graduação em Educação da UFPB.
}

${ }^{4}$ Falar bem e escrever bem significava estar de acordo com a norma culta da língua.

${ }^{5}$ CARVALHO, Felisberto Rodrigues Pereira de. Exercícios de estilo. Rio de Janeiro: Garnier Editores, 1885; RODRIGUES, G. O estilo em ação ou A arte de escrever ensinada pelaprática. São Paulo: Tip. A vapor de Hennies Irmãos, 1895; BILAC, Olavo e BONFIM, Manoel. Livro de composição para o curso complementar das escolas primárias. Rio de Janeiro: Laemmert e editores, 1904; RIBEIRO, Hilario de. Grammática da Infancia (1880); DIAS, Claudino. Exercicios Preparatorios de Composição (1881).

\footnotetext{
${ }^{6}$ Fundado no ano de 1900, o Jornal Do Commercio era um Órgão das Classes Conservadoras do Estado da Parahyba tinha circulação diária. Propriedade de uma sociedade Anonyma da Parahyba, seu editor responsável era Arthur Aquiles (1906). Disponível em: 〈http://ihgp.net〉. Acesso em: 01 de maio de 2014.

${ }^{7}$ Fundado em 2 de fevereiro de 1893, no governo de Álvaro Lopes Machado, A União é o terceiro jornal mais antigo em circulação no Brasil. É um jornal estatal paraibano, matutino, editado na cidade de João Pessoa, seu primeiro diretor foi o industrial e jornalista Tito Silva. O jornal surgiu como órgão do Partido Republicano do Estado da Paraíba, agremiação fundada pelo próprio Álvaro Machado.” No passado,
} 
escreveram em suas páginas nomes como Augusto dos Anjos, Orris Soares, Gama e Melo, José Lins do Rego e José Américo. Disponível em: 〈http://ihgp.net>. Acesso em: 05 de janeiro de 2014.

${ }^{8}$ Esta citação encontra-se na obra de Xavier Junior (1906, p. IV), assinada apenas pelo nome do Jornal União, sem referenciar autor. Em busca nos arquivos do jornal, não foi encontrada nenhuma publicação referente a obra de Xavier Junior nos poucos materiais que tive acesso. A maior parte do acervo dos anos de 1906 e 1907 não estavam disponíveis para pesquisa devido seu estado de conservação.

9 Ao utilizar o termo "espírito" o autor provavelmente estava se referindo a mentalidade infantil em desenvolvimento das crianças.

Recebido: junho-15 Aprovado: outubro-15 